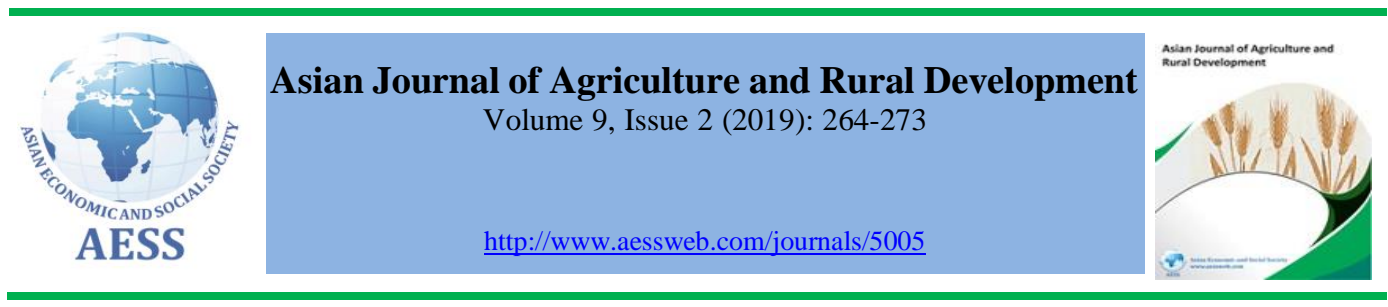

\title{
DETERMINANTS OF BURDEN OF DISEASE AMONG RICE FARMING HOUSEHOLDS IN OGUN STATE, NIGERIA
}

\author{
Aboaba, K. O. ${ }^{a}$, \\ Oyekale, T. O. ${ }^{\text {b }}$, \\ Adewuyi, S. A. ${ }^{\text {a }}$, \\ Adigbo, S. O. ${ }^{\mathrm{c}}$
}

a Department of Agricultural Economics and Farm Management, Federal University of Agriculture, Abeokuta, Nigeria

${ }^{b}$ Institute of Food Security Environmental Resources and Agricultural

Research, Federal University of Agriculture, Abeokuta, Nigeria

${ }^{c}$ Department of Plant Physiology and Crop Production, Federal University of Agriculture, Abeokuta, Nigeria

\aboabakazeem@gmail.com (Corresponding author)

\section{ARTICLE HISTORY: \\ Received: 01-Jul-2019 \\ Accepted: 07-Nov-2019 \\ Online Available: 11-Dec- 2019}

\section{Keywords:}

Burden of disease,

Rice farming,

Households,

Ogun state,

Cost of illness

\begin{abstract}
This study was carried out to indicate the factors, which could determine the burden of disease among rice farming households in Ogun state in Nigeria. Multi-stage sampling procedure was used to select 240 rice farming households. The study showed that nearly all households took drugs or medicines without consulting a doctor or pharmacist. Low level of income (85.33\%), lack of awareness of health facilities $(52.02 \%)$, low level of education $(58.22 \%)$, as well as hindrances in distance and difficult terrains towards health facilities (75.11\%) were indicated as the critical problems being faced by the households from using public health facilities. Sex, household size, offfarm income, distance to health care services and dirt floor of home were positively and significantly considered to influence disease burden, while age, cooperative membership, labor used and health conditions had negative effects. The study concluded that increased distance to health care services increased the burden of diseases of the households. It was therefore, recommended that health facilities should be located nearer to the people's locations to increase its appropriate use. This would gradually improve their health conditions, and thereby reduce the ill-health cost in the long run.
\end{abstract}

\begin{abstract}
Contribution/ Originality
This study examined factors influencing economic burden of diseases among rice farming households. This study will further serve as a guide to government, non-governmental organizations and other stakeholders involved in provision of health care facilities, it will also be a prima facie in adding to the sparse knowledge that exist in the area of factors influencing farmers ill-health cost.
\end{abstract}

DOI: 10.18488/journal.1005/2019.9.2/1005.2.264.273

ISSN (P): 2304-1455/ISSN (E):2224-4433

How to cite: Aboaba K. O., Oyekale, T. O., Adewuyi, S. A. and Adigbo, S. O. (2019). Determinants of burden of disease among rice farming households in Ogun state, Nigeria. Asian Journal of Agriculture and Rural Development, 9(2), 264-273.

(C) 2019 Asian Economic and Social Society. All rights reserved. 


\section{INTRODUCTION}

Since rice is the staple food commodity for many households within the Sub-Saharan Africa, its demand would obviously creep upwards. Its demand in the region had grown at an annual rate of $6 \%$ as a result of increase in population and change in taste of the populace (Ismail et al., 2012). Similarly, demand for rice in Nigeria had grown at the rate of $7.3 \%$ annually, since mid-1970s (Bamidele et al., 2010), whereas on average, every Nigerian consumes $24.8 \mathrm{~kg}$ of rice annually, representing quite a larger percent of total calories intake (Alfred et al., 2014). The production capacity of rice is far below its national supplies, despite its contribution to the food requirement of the population (Ogunsumi et al., 2013). Besides, the number of rice producing farmers in Nigeria is small and are characterized by low output, aging population and very low know-how of technology, as observed by Fasoyiro and Taiwo (2012). In spite of these factors, rice farmers are facing a number of diseases, which prevents them from utilizing their full resources. Since their production capacities are by and large affected, and lead to much reduction in their incomes in particular, and subsequently affect their wellbeing in general, as well accordingly.

Health comprises the complete physical, social, mental, and physiological well-being of an individual, and not merely the absence of disease or infirmity (FAO/WHO, 1992), whereas good health contributes to people's ability to be productive. Since health contributes to one's enrolment and success in school, which in turn is a determinant of future earnings. Also, large out of pocket expenditure as a result of ill-health cost have an impact on financial status and can push people into continuous poverty. However, amidst the alarming report of effects of diseases on farmers, as pointed out by Ajani and Ugwu (2008), 13\% of the household expenditure was spent on treatment of malaria infestation among small scale farmers in Nigeria. Similarly, another recent study valued both the health cost and opportunity cost of a farmer becoming sick once in Nigeria to be $\$ 29$, 225.53 (US\$ 8.1). ${ }^{1}$ This shows that the cost of combating ill-health challenges by the farmers in Nigeria is quite huge.

When considered as a form of resource, health could reduce or increase efficiency because good health for productive agriculture is critically important in challenging the odds against poverty and food insecurity, precautions and improvement in health care, along with adequate and immediate facilities increase the productivity of labour and thereby enhance the economic growth (Ulimwengu, 2009). However, most studies undertaken on health related issues are often diseasespecific, which limits the assessment of the farmers' health conditions (Ugwu, 2006). Similarly, most of the other studies on health focused on occupational health in the medical field, making it impossible to determine the number of people with various illness as a result of agricultural exposure. Nevertheless, the economic impact of agriculture related ill health and injuries require proper and appropriate assessment. As pointed out by IFPRI (2007), poor health affects both productivity and income of the farmers, thereby perpetuating a downward spiral into a vicious cycle of ill health and poverty. Such activities will further inhibit economic growth, development and general well-being of the vast and wider population.

However, at this point we intend to place specific emphasis on studies aimed at understanding the determinants of burden of ill-health among rice farming households in Nigeria, given the importance of this food crop in the specific baskets of food commodities for the average populace. Therefore, this study seeks to fill the existing gap in the body of knowledge with regards to the factors that determine the burden of disease among rice farming households, specifically inclined to describe their personal characteristics, or ascertain various episodes and locate the prevalence of self-reported illness among them, besides identifying the sources of health care services available to the households along with the determination of those factors, which prevents rice farmers from using public health care services.

${ }^{1}$ 1USD equals $\$ 355.99$ 


\section{MATERIALS AND METHODS}

The study was carried out in Ogun State in the southwest geopolitical zone of Nigeria. It lies within latitudes of $60 \mathrm{~N}$ and $80 \mathrm{~N}$ and longitude $20 \mathrm{E}$ and $50 \mathrm{E}$ with an estimated population of 3,728,098 according to the 2006 National Census (NPC, 2006). The state has conducive climatic and environmental conditions that support the cultivation of food crops such as rice, maize, cassava, plantain, etc. Multistage sampling technique was employed for this study, the stage was a purposive selection of a block from each of the four (4) Agricultural Development Project (ADP) zones in the state, the second stage was a purposive selection of a major rice producing cell from each of the sampled blocks, the third stage was a random selection of three villages from the sampled cells, last stage entails purposive selection of twenty (20) rice farming households from the sampled villages, thus, making a total sample size of two hundred and forty (240) rice farming households, however, during the process of data clean up only two hundred and twenty five (225) questionnaires were fit for analysis. Data for this study was obtained from primary source, primary data was collected from rice farming household via structured interview guide, the data collected was on socioeconomic characteristics such as age, sex, level of education, household size, primary occupation, secondary occupation, income, etc. question on prevalence and episodes of diseases, cost of illness etc. Data for this study were analyzed with both descriptive and econometrics techniques.

\subsection{Cost of illness (economic burden of disease)}

Cost of illness provides a monetary equivalent of diseases burden (Adekunle et al., 2016). This study adopted and modified cost of illness procedure used by Akinbode et al. (2011) by adding preventive cost such as cost of mosquito nets, mosquito coils, etc. to the total economic cost of illness and this is expressed as;

Economic Cost $=\sum_{j=0}^{n}\left(\mathrm{~F}_{\mathrm{c}}+\mathrm{T}_{\mathrm{c}}+\mathrm{P}_{c}\right)$

Where;

$F_{c}$ is the financial cost of illness and expressed as;

$\mathrm{F}_{\mathrm{c}}=\sum_{j=0}^{n}\left(\mathrm{Fd}+F_{m}+F_{t}+F_{s u}\right)$

Where;

$F_{d}=$ financial cost of drugs, herbs, etc. ( $)$

$\mathrm{F}_{\mathrm{m}}=$ financial cost of medical consultancy ( $\left.\mathrm{N}\right)$

$\mathrm{F}_{\mathrm{t}}=$ financial cost of travel ( $)$

$\mathrm{F}_{\mathrm{su}}=$ financial cost of subsistence (feeding) (N) and

$\mathrm{T}_{\mathrm{c}}$ is the total time cost of illness expressed as;

$\mathrm{T}_{\mathrm{c}}=\sum_{j=0}^{n}\left(\left[\left(T_{s i} * a_{s i} * w\right)+\left(T_{c i} * a_{c i} * w\right)\right]\right.$

Where;

$T s i=$ number of days of forgone production by the sick individual (s)

To calculate the number of days of forgone production it was assumed that average working condition prevail and adult male work for about 8 hours a day as used by Akinbode et al. (2011). Thus, the actual total hours devoted to farm work were converted to male adult equivalent by multiplying those of male by 1 and those of female by 0.75 and those of children by 0.5 .

$\mathrm{a}=$ age coefficients (number)

The age coefficient "a" represents productivity coefficient and this takes on the following values following Sauerborn et al. (1996) and World Bank (1993): 
Age $<17$ years $=0.5$

$18-40$ years $=1$

$41-55$ years $=0.75$

$56-65$ years $=0.67$ and

$>65$ years $=0.5$.

$\mathrm{s}=$ number of sick individual (s)

$\mathrm{w}=$ daily wage rate $(\mathrm{N})$

$T c i=$ number of days of forgone production by caregiver (s)

$\mathrm{c}=$ Number of caregiver $(\mathrm{s})$ and

$\mathrm{P}_{c}$ is the preventive cost such as; cost of mosquito net, coil, balm, etc.

\subsection{Multiple regression analysis}

The determinants of disease burden among the rice farming households was estimated using ordinary least square regression model, The explicit form of the equation is specified as;

$G=\beta_{0}+\beta_{1} Z_{1}+\beta_{2} Z_{2}+\beta_{3} Z_{3}+\beta_{4} Z_{4}+\beta_{5} Z_{5}+\beta_{6} Z_{6}+\beta_{7} Z_{7}+\beta_{8} Z_{8}+\beta_{9} Z_{9}+\beta_{10} Z_{10}+\beta_{11} Z_{11}+\beta_{12} Z_{12}+\mu \ldots$

Where;

$\mathrm{G}=$ economic cost of illness (

$\mathrm{Z}_{1}=$ age of farmers (years)

$Z_{2}=\operatorname{sex}($ male $=1$, female $=0)$

$\mathrm{Z}_{3}=$ household size (number of people)

$\mathrm{Z}_{4}=$ off-farm income $(\mathrm{N})$

$\mathrm{Z}_{5}=$ level of education (years)

$\mathrm{Z}_{6}=$ cooperative membership $($ member $=1$, otherwise $=0)$

$\mathrm{Z}_{7}=$ labor used (hired labor $=1$, otherwise $=0$ )

$\mathrm{Z}_{8}=$ distance to health care services (kilometers)

$\mathrm{Z}_{9}=$ health condition $(\mathrm{good}=1$, otherwise $=0)$

$\mathrm{Z}_{10}=$ access to clean drinking water (inaccessible $=1$, otherwise $=0$ )

$\mathrm{Z}_{11}=$ access to adequate sanitation (inaccessible $=1$, otherwise $=0$ )

$\mathrm{Z}_{12}=$ floor of home (un-cemented $=1$, otherwise $=0$ )

Where $\beta_{0^{-}} \beta_{12}$ are parameters that will be estimated and

$\mu=$ disturbance or error term.

\section{RESULTS AND DISCUSSION}

\subsection{Socio-economic distribution}

Results on table 1 revealed that a larger proportion $(73.33 \%)$ of the rice farming household were headed by male while $26.67 \%$ of the rice farming households were headed by female, the dominance of male over female was because rice production is tedious and requires more strength that female may not be able to provide, more than a quarter $(39.56 \%)$ of the rice farming household heads are greater than 60years, this implies that majority of the rice farming household heads are old, not energetic and non-vibrant which is an indication that their productivity might have started to fall. more than a quarter $(37.78 \%)$ of the rice farming household heads did not had formal education, the implication is that this may further prevent them from adopting innovations related to agricultural as well as health practices, almost half (43.56\%) of the rice farming household heads are into processing of agricultural produce and this may be attributed to the fact that farming was the major activities of the household heads. 
Table 1: Socio-economic characteristics of respondents

\begin{tabular}{lcc}
\hline Variable & Frequency & Percentage \\
\hline Sex & 60 & \\
Female & 165 & 26.67 \\
Male & 225 & 73.33 \\
Total & & 100.00 \\
Age & 11 & \\
<=30years & 31 & 4.89 \\
31-40years & 47 & 13.78 \\
41-50years & 47 & 20.89 \\
51-60years & 89 & 20.89 \\
$>60 y e a r s$ & 225 & 39.56 \\
Total & & 100.00 \\
Educational Level & 85 & \\
Non Formal & 77 & 37.78 \\
Primary & 63 & 34.22 \\
Secondary & 225 & 28.00 \\
Total & & 100.00 \\
Secondary Occupation & 98 & \\
Agricultural produce processing & 57 & 43.56 \\
Trading & 55 & 25.33 \\
Artisans /craft & 15 & 24.44 \\
Others & 225 & 6.67 \\
Total & & 100.00 \\
\hline
\end{tabular}

Source: Field Survey, 2018

\subsection{Self-reported illness episodes}

Table 2 revealed that out of 1243 illness episodes reported by the rice farming households within the period of six months, malaria contributed most $(17.14 \%)$ of the total illness experienced, $16.89 \%$ of the illness was due to back pain, $15.69 \%$ of the total illness was due to fever, $6.60 \%$ of the illness was due to guinea worm, $8.29 \%$ of the illness was due to typhoid, $4.51 \%$ of the illness was due measles, $9.49 \%$ of the illness was due to rheumatism, $5.31 \%$ of the illness was due to tuberculosis while $16.09 \%$ of the illness was due to waist pain, malaria infestation contributed mostly to the total illness experienced by the rice farming households followed by back pains, waist pain, fever, rheumatism, typhoid, guinea worm, tuberculosis and measles respectively. This result supports the findings of Adekunle et al. (2016) that found out that malaria contributed most $(41.92 \%)$ of the total illness among farmers in Ogun state.

Table 2: Self-reported illness episodes

\begin{tabular}{lcc}
\hline Variable & Frequency (Episodes) & Percentage \\
\hline Perceived illness & 210 & \\
Back pain & 195 & 16.89 \\
Fever & 213 & 15.69 \\
Malaria & 82 & 17.14 \\
Guinea worm & 103 & 6.60 \\
Typhoid & 56 & 8.29 \\
Measles & 118 & 4.51 \\
Rheumatism & 66 & 9.49 \\
Tuberculosis & 200 & 5.31 \\
Waist pain & 1243 & 16.09 \\
Total & & 100.00 \\
\hline
\end{tabular}

Source: Field Survey, 2018 


\subsection{Average Ill-health prevalence}

Table 3 revealed the prevalence of self-reported illness among rice farming households within the period of six months, the result revealed that on the average rice farming households experienced back pains illness 14 times, fever illness was suffered 6 times, malaria illness was suffered 10 times, guinea worm illness was suffered once, typhoid illness was experienced 3 times, measles illness was experienced once, rheumatism illness was suffered 5 times, tuberculosis illness was suffered once while waist pain illness was suffered 14 times, this implies that on average, rice farming households experienced back pain and waist pain more than other illness followed by malaria, fever, rheumatism, typhoid, guinea worm, measles and tuberculosis respectively.

\section{Table 3: Prevalence of self-reported Illness}

\begin{tabular}{lc}
\hline Variable & Mean prevalence \\
\hline Illness & 14 \\
Back pain & 6 \\
Fever & 10 \\
Malaria & 1 \\
Guinea worm & 3 \\
Typhoid & 1 \\
Measles & 5 \\
Rheumatism & 1 \\
Tuberculosis & 14 \\
Waist pain & \\
\hline
\end{tabular}

Source: Field Survey, 2018

\subsection{Health care services source}

Table 4 revealed that more than a quarter $(37.78 \%)$ of the rice farming households took drugs without consulting a doctor or pharmacist, almost a quarter $(24.44 \%)$ of the rice farming households seek health care services from government clinics, more than a quarter $(29.33 \%)$ of the rice farming households seek health care services from private clinics while lower proportion $(8.44 \%)$ of the rice farming households seek health care services from traditional healers, this implies that most of the households did not patronize health care services where drugs can be prescribed for the treatment of their illness. This could be as a result of lack of money to access health care services that probably seems expensive to them; this result is in line with the findings of Adebayo et al. (2012) and Oparinde et al. (2018) that reported that most of the farmers took drugs without consulting medical practitioners.

Table 4: Health care services source

\begin{tabular}{lcc}
\hline Variable & Frequency & Percentage \\
\hline Government clinic & 55 & 24.44 \\
Private clinic & 66 & 29.33 \\
Traditional healers & 19 & 8.44 \\
Self-medication & 85 & 37.78 \\
Total & 225 & 100.00 \\
\hline
\end{tabular}

Source: Field Survey, 2018

\subsection{Constraint faced in seeking public health care services}

Table 5 revealed that larger proportion $(85.33 \%)$ of the rice farming households did not use public health care services as a result of low level of income; this implies that most of the households lack adequate funds to seek for public health care services, this result conform to the findings of Nnonyelu and Nwankwo (2014). More than half (56.89\%) of the rice farming households were of the view that poor quality of health care services in government clinics was not the reason why they 
were not using public health care services, this implies that majority of the households were satisfied with the quality of health care services delivered by government clinics but failed to use those clinics, more than half $(52.02 \%)$ of the rice farming households opined that lack of awareness of public health care facilities was the reason why they were not using government clinics, more than half $(58.22 \%)$ of the rice farming households opined that low level of education prevented them from using public health facilities, this result supports the findings of Moore et al. (2011) and Agha (2000). Larger proportion (75.11\%) of the rice farming household head were the view that the longer distance and difficult terrain of public health centers discouraged them from using them.

Table 5: Constraints facing the use of public health care services

\begin{tabular}{lcc}
\hline Constraints & Frequency & Percentage \\
\hline Low level of income & 33 & 14.67 \\
No & 192 & 85.33 \\
Yes & 225 & 100.00 \\
Total & 128 & 56.89 \\
Poor quality of health care services & 97 & 43.11 \\
No & 225 & 100.00 \\
Yes & & 48.44 \\
Total & 109 & 51.56 \\
Lack of awareness of health care facilities & 116 & 100.00 \\
No & 225 & 41.78 \\
Yes & & 58.22 \\
Total & 94 & 100.00 \\
Low level of education & 131 & 24.89 \\
No & 225 & 75.11 \\
Yes & & 100.00 \\
Total & 56 & \\
Distance and difficult terrain of health facilities & 169 & \\
No & 225 & \\
Yes & & \\
Total & & \\
\hline
\end{tabular}

Source: Field Survey, 2018

\subsection{Determinants of burden of disease}

The determinants of disease burden was estimated using ordinary least square regression, as shown on table 6 , the diagnostic test; $\mathrm{R}^{2}$, probability of $\mathrm{F}$ and Variance Inflation Factor attest to the fitness of the result, the $\mathrm{R}^{2}$ revealed that $51.3 \%$ variation in disease burden was jointly explained by the significant explanatory variables, the F-value revealed that the variables in the model are fit to explain the determinant of disease burden, the mean VIF revealed that there is absence of multicollinearity, this implies that the model was rightly specified. The result revealed that age, sex, household size, off-farm income, cooperative membership, labor used, distance to health care services, health condition and floor of home significantly influence disease burden of rice farming households.

The coefficient of age revealed that increase in age reduces the economic burden of disease; this implies that if age of the household heads increases by one year, the cost of illness would decreases by $1,977.8$ (USD 5.5), this implies that older farmers tends to spend less on their health, this may be because aged farmers rely on self-medication practices, the coefficient of sex implies that the economic cost of illness of households headed by male increases by $\$ 67,142.42$ (USD 186.5) compared with households headed by females, this may be because majority of the rice farming households are headed by male, the coefficient of household size revealed that as household size increases the cost of illness also increases, this implies that if the size of the household increases by 
one person the economic cost of illness would increase by $\$ 15,614.92$ (USD 43.38), this is so because the larger the household size the higher the likelihood of household member to be sick thereby raising the cost of their treatment, the coefficient of off-farm income revealed that if the off-farm income increases by $\$ 1$ (USD 0.003 ) the cost of illness will increase by 0.14 (USD 0.0004), this implies that rice farmers that diversify their livelihood source into off-farm activities spend more on their health, the coefficient of cooperative membership revealed that the cost of illness of rice farmers that belonged to cooperative association would decreases by $\$ 50,322.2$ (USD 139.8) compared to their counterparts that did not belong to cooperative society, the coefficient of labor used revealed that cost of illness of farmers that use mostly hired labor reduces by $21,234.55$ (USD 60) compared with those that used own labor, family labor or communal labor, this is so because using hired labor reduces the chance of exposing family labor to occupational risk emanating from agricultural activities thereby reducing ill health as well as the cost of combating ill health, the coefficient of distance to health care provider revealed that increase in distance health care provider increases the burden of disease, this implies that $1 \mathrm{Km}$ increase in distance to health care provider increase the cost of illness by 660.94 (USD 1.8), this is so because increase in distance to health care provider increases transportation cost thereby increasing cost of illness, the coefficient of health condition revealed that rice farmers whose health conditions are good spend $\$ 55,027.36$ (USD 152.9) less on their health compared to their counterparts, this implies that rice farmers with good health condition spend less on their health compared to their counterparts, the coefficient of floor of home revealed that rice farmers whose floor of home was not cemented spend 153,183 (USD 425.5) more on their health compared to their counterparts with cemented floor.

Table 6: Multiple regression estimates of determinants of disease burden

\begin{tabular}{lcccc}
\hline Variable & Coefficient & Standard Error & t-value & P-value \\
\hline Constant & $132901.900^{* * *}$ & 30917.960 & 4.300 & 0.000 \\
Age & $-1977.800^{* * *}$ & 404.757 & -4.890 & 0.000 \\
Sex & $67142.420^{* * *}$ & 12593.500 & 5.330 & 0.000 \\
Household size & $15614.920^{* * *}$ & 2141.353 & 7.290 & 0.000 \\
Marital status & -837.478 & 7996.793 & -0.100 & 0.917 \\
Off-farm income & $0.135^{*}$ & 0.069 & 1.960 & 0.052 \\
Level of education & 405.593 & 1016.849 & 0.400 & 0.690 \\
Cooperate membership & $-50322.200^{* * *}$ & 11824.830 & -4.260 & 0.000 \\
Labour used & $-21234.550^{*}$ & 10992.800 & -1.930 & 0.055 \\
Distance to health care services & $660.943 * * *$ & 204.627 & 3.230 & 0.001 \\
Health condition & $-55027.360^{* * *}$ & 13308.140 & -4.130 & 0.000 \\
Access to clean drinking water & -490645.900 & 372757 & -1.320 & 0.190 \\
Access to adequate sanitation & -96696.560 & 349386 & -0.280 & 0.782 \\
Floor of home & $153183 * * *$ & 325390 & 4.710 & 0.000 \\
Diagnostic Test & & & & \\
$\mathrm{R}^{2}$ & 0.513 & & & \\
Prob > F & 0.000 & & & \\
F(13, 211) & 22.400 & & & \\
Mean VIF & 1.560 & & & \\
\hline
\end{tabular}

$* * *, * *$ and $*$ represents significant at $1 \%, 5 \%$ and $1 \%$ level of significance

\section{CONCLUSION AND RECOMMENDATIONS}

This study has attempted to determine various factors, which directly or indirectly influence the burden of disease among rice farming households in the Ogun State of Nigeria. The findings clearly revealed that majority of the rice farmers were male, aged and with no formal education. The results further revealed that malaria infestation contributed with the highest ratio within the total 
illness experienced by the rice farming households. Some underwent severe backaches and pain in the waist more than other illnesses, followed by the earlier mentioned malaria, fever, rheumatism, typhoid, guinea worm, measles and tuberculosis, respectively in the descending order. The study also revealed that rice farming households took medicines and drugs without consulting any doctor or a pharmacist, because of lack of awareness of health facilities, and low level of education. It was also found that low level of income, and distance from and difficult access to public health centers are other problems faced by the households in making good use of public health facilities. The results of the study further disclosed that age, sex, household size, off-farm income, cooperative membership, labor used, distance to health care services, health condition and dirt floor at home significantly influenced the burden of disease among rice farming households. The study also concluded finally that increase in distance to health care services, increase in household size, increase in off-farm income and un-cemented floor of households were other factors causing an apparent increase in the burden of their diseases, whereas farmers with good and sound health conditions spend less in this head. Therefore this study recommends undoubtedly and without hesitation that more awareness creation and informative know-hows about the need to patronize qualified medical personnel and public health facilities should be provided, instead of using selfmedication measures among farmers. Moreover, health care amenities should be located closer to the people's reach for immediate and rapid approach, as this would help to reduce their financial costs and in return could thereby, increase the usage of such adequate and requisite facilities.

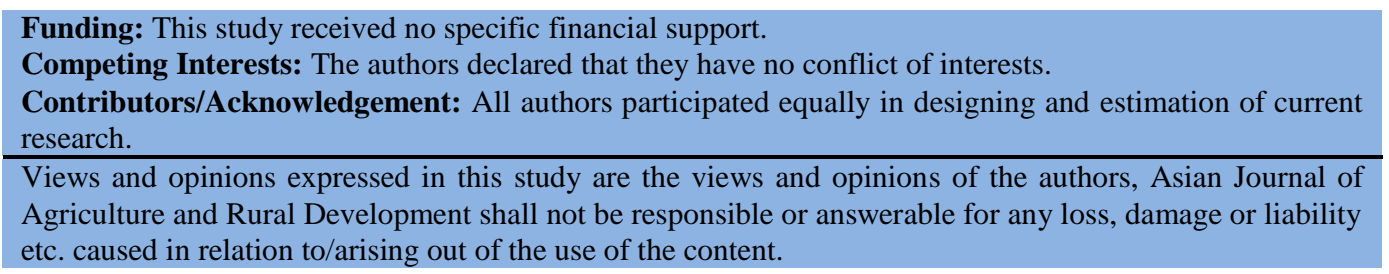

\section{References}

Adebayo, M. G., Shittu, A. M., Obayelu, A. E. \& Sam-Wobo, S. O. (2012). Health and production efficiency of fram households in Ogun state, Nigeria. In: Idowu, E. O., Ayanwale, A. B., Bamire, A. S., \& Adejobi, A. O. (Editors). Agriculture in the National Transformation Agenda: The Policy Mix. Proceedings of Annual Conference of the Nigerian Association of Agricultural Economists, 25th-27th September, 2012, Obafemi Awolowo University, Ile-Ife, Nigeria. 171-187.

Adekunle, A. K., Adekunle, C. P., \& Aihonsu, J. O. Y. (2016). Effect of health condition on technical efficiency of small-scale crop farmers in yewa division of Ogun State, Nigeria. Nigerian Journal of Agriculture, Food and Environment, 12(2), 138-143.

Agha, S. (2000). The detriments of infant mortality in Pakistan. Social Science and Medicine, 51, 199-208.

Ajani, O. I. Y., \& Ugwu, P. C. (2008). Impact of adverse health on agricultural productivity of farmers in Kainji Basin, North Central Nigeria using a stochastic production frontier approach. Trends in Agriculture Economics, 1(1), 1-7. doi.org/10.3923/tae.2008.1.7.

Akinbode, S. O., Dipeolu, A. O., \& Ibrahim, D. A. (2011). Effects of disease burden on technical efficiency among lowland rice farming households in north central Nigeria. World Journal of Agricultural Sciences, 7(3), 359-369.

Alfred, S. D. Y., \& Adekayode, A. B. (2014). Consumers' attitude towards local rice production and consumption in Ondo state, Nigeria. Journal of Agricultural and Rural Development, 6(7), 242-248. doi.org/10.5897/jaerd11.014.

Bamidele, F. S., Abayomi, O. O., \& Esther, O. A. (2010). Economic analysis of rice consumption patterns in Nigeria. Journal of Agricultural Science and Technology, 12, 1-11. 
Fasoyiro, S. B., \& Taiwo, K. A. (2012). Strategies for increasing food production and food security in Nigeria. Journal of Agricultural \& Food Information, 13(4), 338-355. doi.org/10.1080/10496505.2012.715063.

Food and Agricultural Organization/World Health Organization (1992). International Conference on Nutrition and Development. A Global Assessment. 3, 46.

International Food and Policy Research Institute Bulletin (2007). Last accessed February, 2008. from http://www.fpri.org.

Ismail, A. M., Johnson, D. E., Ella, E. S., Vergara, G. V., \& Baltazar, A. M. (2012). Adaptation to flooding during emergence and seedling growth in rice and weeds, and implications for crop establishment. AoB PLANTS pls019; doi:10.1093/aobpla/pls019, Retrieved on 18th November, 2012 from http://aobpla.oxford journals.org/content/2012/pls019.full.pdf+html.

Moore, B. M., Alex-Hart, B. A., George, I. O. (2011). Utilization of Health Care Services by Pregnant Mothers during Delivery: A Community based study in Nigeria. Journal of Medicine and Medical Science, 2(5), 864-867.

National Population Commission (NPC) (2006). National Population and Housing census statistics in Nigeria.

Nnonyelu, N. A., \& Nwankwo U. I. (2014). Social determinants of differential access to health services across five states of southeast Nigeria. European Scientific Journal, 3, 286-296.

Ogunsumi, L. O, Ajayi, A., Amire, C. M., \& Williams, S. (2013). Sustainability of agricultural transformation agenda. the place of rice farmers in Ogun state Nigeria. Research on Humanities and Social Sciences, 3(13), 66-78.

Oparinde, L.O., Ogunbusuyi O., Aturamu O. A., Oladipo C.O. (2018). Food crop farmers' health and poverty status nexus in Ondo state, Nigeria. Journal of Poverty, Investment and Development, 43, 47-55.

Sauerborn, R. N., Noutaga, A., Hiem, M., \& Diesfeld, H. F. (1996). Seasonal variation of household costs of illness in Burkina Faso. Social Science and Medicine, 43(3), 281-290. doi.org/10.1016/0277-9536(95)00374-6

Ugwu, P. C. (2006). Effect of farmers health on the agricultural productivity of the principal farm operator in Borgu Iga of Niger state. M.Sc. project, (Unpublished) University of Ibadan, Ibadan, Nigeria.

Ulimwengu, J. (2009). Farmers' health and agricultural productivity in rural Ethiopia. International Food Policy Research Institute (IFPRI), Washington, DC.

World Bank (1993). World development report: investing in health. Oxford University Press, New York. 